\title{
THE CONTROL OF VENTRICULAR FUNCTION IN MAN*
}

\author{
BY
}

\author{
EUGENE BRAUNWALD
}

From the Cardiology Branch, National Heart Institute, National Institutes of Health, Bethesda, Maryland, U.S.A.

\author{
Received May 12, 1964
}

Since William Harvey's discovery of the prime function of the heart as a pump, clinicians and physiologists have marvelled at the extraordinary ability of this organ to adjust its performance almost instantaneously to meet the rapidly changing requirements of the peripheral tissues. Probably no other aspect of cardiovascular research has received as much effort and attention as the attempts to gain an understanding of the systems that control the heart's ability to propel blood through the circulatory system. During the past century, this problem has been investigated at many levels; from isolated extracts of contractile proteins, to isolated atrial and papillary muscle preparations, to isolated hearts and heart-lung preparations, and anæsthetized open-chest dogs, as well as closed-chest, unanæsthetized dogs.

Among the most significant contributions to these investigations were those that came from the laboratories of Professors Frank (1895) and Starling (1918). These investigators extended to the heart the earlier observations of Fick (1882), Kries (1892), and Blix (1895) who had already established for skeletal muscle that the length and tension of the muscle at the time of stimulation determined the magnitude of its contractile response. The immediate impact of this work, as presented by Starling in his Linacre lecture (1918), requires little emphasis at this time. However, during the past 15 years some investigators have challenged the importance, indeed even the applicability, of the Frank-Starling principle in the regulation of cardiac performance in intact man. Until quite recently the techniques available to the clinical investigator have not permitted a definitive answer to the important question of the control of ventricular function in man, and prevailing opinions have of necessity been based primarily upon extrapolations from animal experiments, as well as on indirect measurements in patients. During the past few years, however, the refinement of methods that permit a detailed study of the circulation in man has made possible a direct attack on this fundamental question. It is the objective of this presentation to review the results of a series of experiments directed towards elucidating the role of two basic mechanisms of cardiac adjustment; (1) the Frank-Starling principle, i.e. the dependence of the mechanical activity of the heart on the ventricular end-diastolic volume and pressure, and (2) the adrenergic nervous system, changes in the activity of which alter the humoral environment of the heart muscle and thereby permit variations in ventricular performance at any given level of end-diastolic volume or pressures.

These investigations were begun by asking a simple question: "How does changing the length of a segment of human myocardium affect its contractile activity?" It was possible to obtain an answer by sewing a specially modified Walton-Brodie strain gauge arch to the right ventricle of 10 patients and to the left ventricle of 1 patient, at the time of cardiac operation. This instrument permits the controlled alteration of the length of the myocardial segment to which it is attached, as well as measurement of the tension exerted by this segment of myocardium throughout the cardiac cycle. In all

* The third Haile Selassie Lecture delivered at the Royal College of Physicians, London, on April 20, 1964, under the auspices of the National Heart Hospital. 
11 patients studied, it was noted that as myocardial length was increased, the end-diastolic tension tended to rise slightly at first, but with further stretching the tension increased more strikingly (Fig. 1). As the segment was stretched the maximal systolic tension that it developed increased more than did its resting tension. Thus, within limits, the active or developed tension rose as the myocardial segment increased in length. In 5 patients the active tension declined after the myocardial segment had been stretched to values ranging between 15 and 50 per cent above baseline length, i.e. a descending limb of the length-active tension relation was evident (Fig. 1). No change in the duration of the active tension state occurred with progressive stretching of the myocardial segment (Fig. 2), and changes in the rate of development of tension paralleled the changes in the active tension (Fig. 3). Fig. 3 also shows the relation between resting tension and active (developed) tension. The ascending limb of the curve is steep, i.e. the active tension rises abruptly with relatively small rises in resting tension. These observations indicated that functioning human myocardium behaves in accordance with the Frank-Starling principle (Aygen and Braunwald, 1962).

More recently we have extended these studies to an examination of the mechanical activity of the papillary muscle excised from the left ventricle of patients at the time of complete replacement of the mitral valve. When mounted in a suitable bath, these isolated portions of the human heart can respond to electrical stimulation and maintain excellent function for more than 12 hours. The resting and active length-tension curves obtained from such tissue resemble those obtained from the heart in situ (Sonnenblick et al., 1964).

Inspection of the shape of the curves in Fig. 1 and 3 also provided information of potential clinical significance. The relative flatness of human myocardial resting length-tension curves with small degrees of stretching (Fig. 1) is of importance in limiting the rise of ventricular end-diastolic pressure, and therefore of atrial and venous pressures, for any given augmentation of myocardial length. Conversely, the relative steepness of the curve relating resting tension to active tension (Fig. 3) indicates that substantial augmentation of the force developed by the ventricle during systole is possible with relatively small increases in resting tension. It is likely that ventricular hypertrophy can modify the resting length-tension curve in a manner so that larger rises of ventricular end-diastolic pressure are necessary for any given increase in the ventricular end-diastolic volume. From other experiments (Braunwald, Frye, and Ross, 1960b), it seems unlikely that the linear external dimensions of the mammalian heart in situ can increase acutely by more than 15 to 20 per cent, and it is therefore suggested that only the initial portion of the curves illustrated in Fig. 1 and 3 describes the relation that exists in most physiological circumstances.

It might properly be asked whether the function of an isolated papillary muscle, or of a segment of myocardium in situ, in which the length is controlled while the activity of the remainder of the heart remains unchanged, is of any relevance to the activity of the entire heart. In order to answer this question, studies were carried out on patients in whom beat-to-beat alterations in left ventricular end-diastolic volume and pressure occurred. In patients with mitral stenosis, the obstruction to left atrial emptying prevents the left ventricle from filling rapidly during early diastole.

Accordingly, it might be anticipated that in patients with mitral stenosis, and irregular ventricular rates due to atrial fibrillation, beat-to-beat variations in the filling of the left ventricle take place due to alterations in the duration of the filling period. It was considered that if Starling's law of the heart operated in patients with mitral stenosis, the characteristics of each left ventricular contraction should be a function of the previous end-diastolic fibre length or end-diastolic pressure, i.e. beats evidencing a relatively greater force of ventricular contraction should be preceded by greater end-diastolic fibre lengths and filling pressures than beats evidencing a relatively smaller force of ventricular contraction. On the other hand, if Starling's law did not operate in these patients, then no clear relation should be evident between ventricular end-diastolic fibre length or end-diastolic pressure and the characteristics of the subsequent contraction.

A Whitney mercury-in-rubber gauge was sewn to the left ventricle of 13 patients with mitral stenosis and atrial fibrillation at the time of mitral commissurotomy (Braunwald et al., 1960a). The length of the segment of left ventricle between the points of attachment of the gauge was recorded 


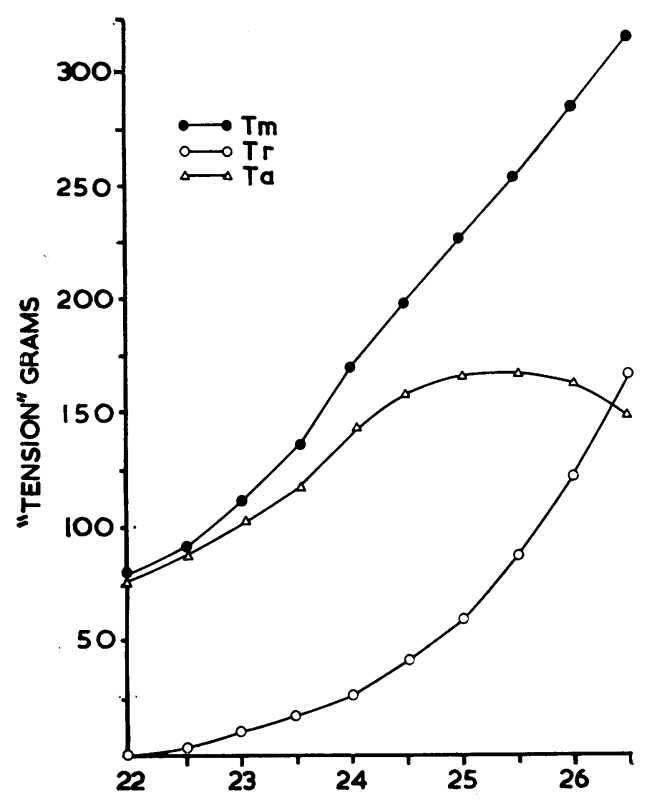

MYOCARDIAL SEGMENT LENGTH ( $\mathrm{mm}$.)

FIG. 1.-Relationships between myocardial segment length, resting tension $\left(T_{r}\right)$, maximal tension $\left(T_{m}\right)$, and active tension $\left(T_{a}\right)$, from the right ventricle of a patient with a ventricular septal defect (Aygen and Braunwald, 1962).

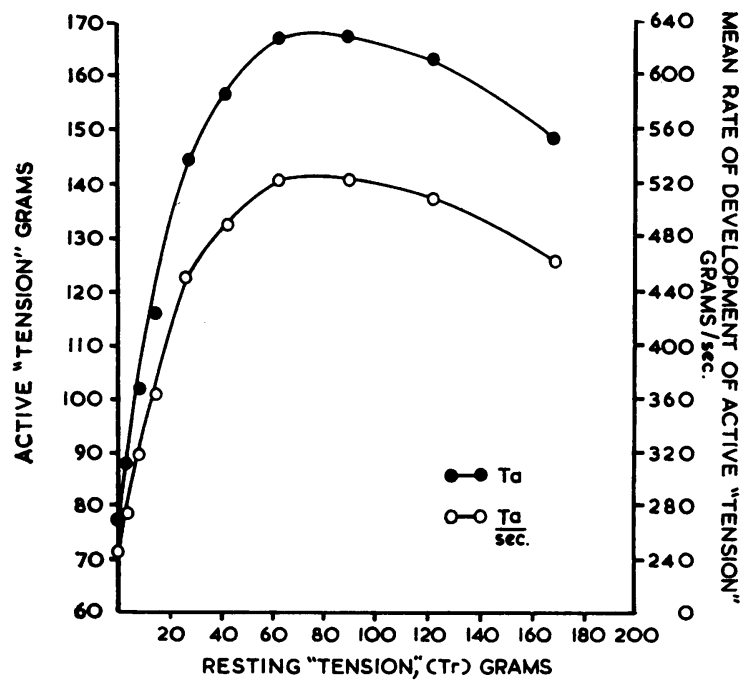

Fig. 3.-Relationships between resting tension $\left(T_{r}\right)$, active tension $\left(\mathrm{T}_{\mathrm{a}}\right)$, and the mean rate of development of active tension $\left(\mathrm{T}_{\mathrm{a}} / \mathrm{sec}\right.$.) (Aygen and Braunwald, 1962).

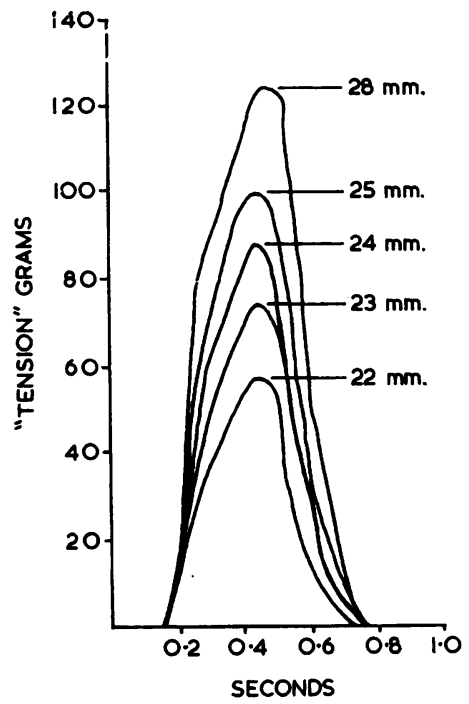

FIG. 2.-Superimposed myocardial tension tracings obtained sequentially from various lengths. Note that the time of peak tension, and the duration of systole remain constant (Aygen and Braunwald, 1962).

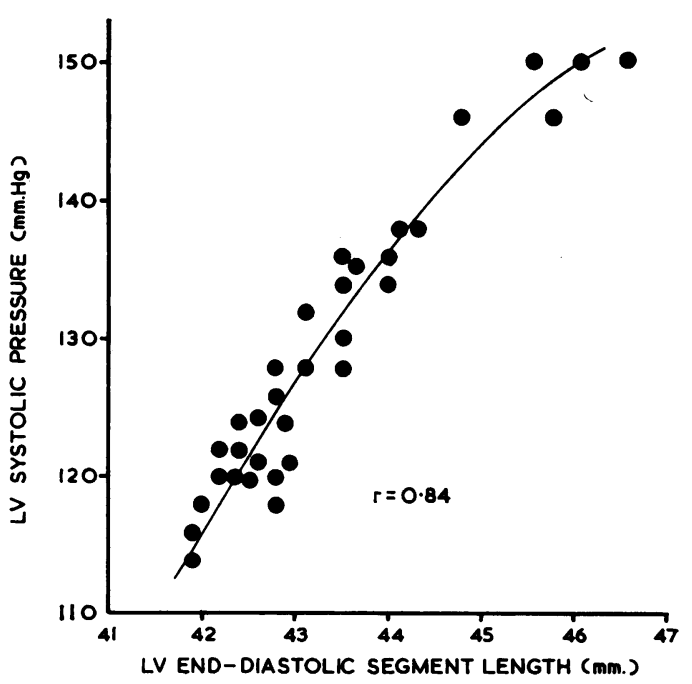

FIG. 4.-Graph depicting relation between the left ventricular (LV) end-diastolic segment length and the systolic pressure of the subsequent beat. Each point represents a single cardiac cycle (Braunwald et al., 1960a). 


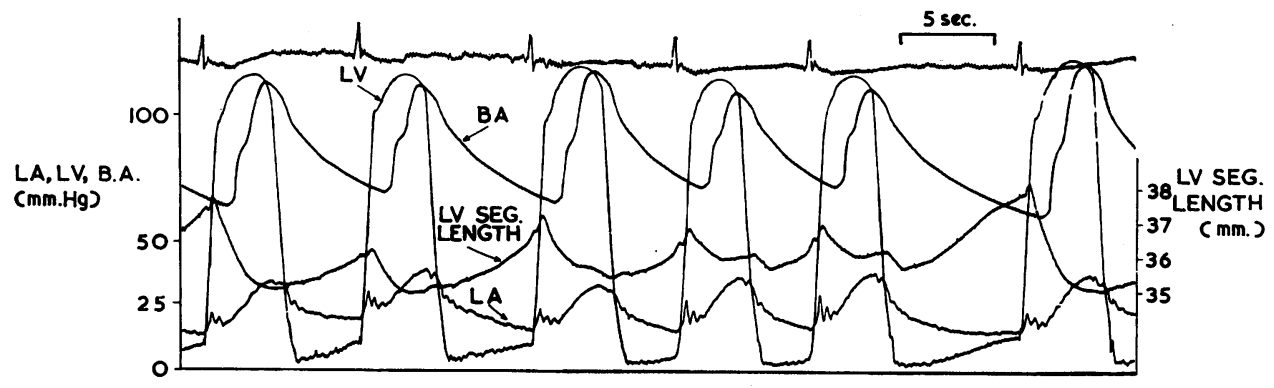

FIG. 5.-Simultaneous recording of electrocardiogram, left ventricular (LV), brachial artery (BA), and left atrial (LA) pressure pulses, as well as left ventricular segment length (LV Seg. Length) (Braunwald et al., 1960a).

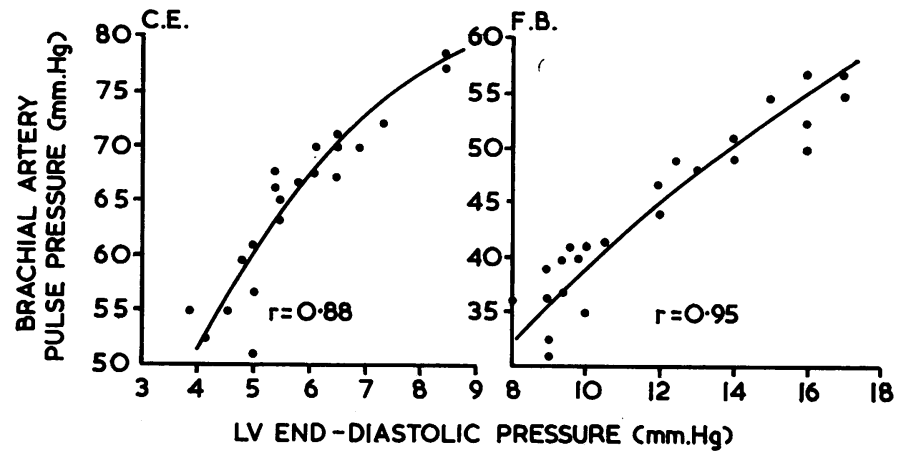

Fig. 6.-Typical relations between left ventricular end-diastolic pressure and the brachial artery pulse pressure in two patients studied by transseptal left heart catheterization (Braunwald $e t$ al., 1960a).

'continuously, along with the left atrial, left ventricular, and systemic arterial pressures (Fig. 5). It was seen that the mechanical activity of the left ventricle during each contraction could be related to the left ventricular end-diastolic segment length, or to the end-diastolic pressure, just preceding the onset of the contraction under consideration. The mechanical activity of the left ventricle was assessed by measuring the left ventricular peak systolic pressure, the brachial artery pulse pressure, the tension-time index, and the duration of systole. The relation between ventricular end-diastolic segment lengths and one of these indices during a sequence of consecutive cardiac cycles is shown in Fig. 4. Similar relations were observed between both end-diastolic segment length and pressure and all four indices of the mechanical activity of the left ventricle. Thus, from the studies carried out at the time of operation, it is evident that regardless of the manner in which the characteristics of ventricular contractions are assessed, the left ventricular end-diastolic fibre length, as reflected by the left ventricular end-diastolic segment length, appears to be a fundamental determinant of the force of ventricular contraction.

In order to determine whether the close correlation between the characteristics of ventricular contraction and of the left ventricular end-diastolic pressure which were apparent in the open-chest anæsthetized patients studied at operation, exist also in intact unanæsthetized patients, observations were then carried out on patients in the course of transseptal left heart catheterization (Ross, Braunwald, and Morrow, 1959). It was seen that the correlations between left ventricular enddiastolic pressure and the characteristics of the subsequent ventricular contraction in the intact 


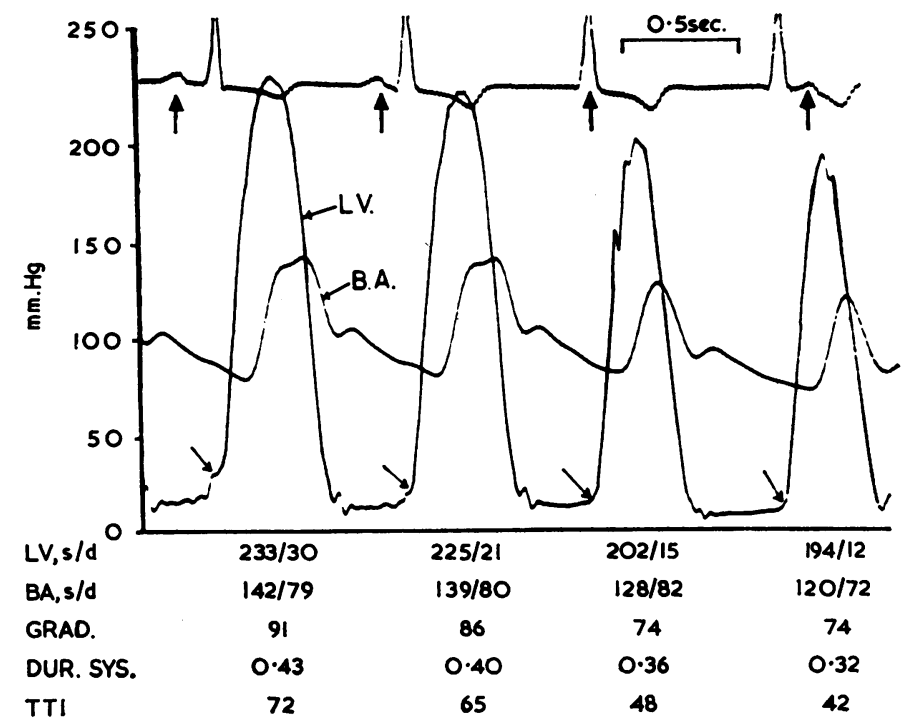

FIG. 7.-Simultaneously recorded left ventricular (LV) and brachial artery (BA) pressure pulses in a patient with aortic stenosis and atrio-ventricular dissociation. The vertical arrows near the top designate the $\mathbf{P}$ waves of the cardiogram; the oblique arrows indicate the $\mathrm{LV}$ end-diastolic pressure. The figures below each beat indicate the pertinent hæmodynamic measurements. $\mathbf{S} / \mathrm{d}=$ systolic/diastolic in $\mathrm{mm}$. Hg. GRAD.=pressure gradient in $\mathrm{mm}$. $\mathrm{Hg}$ between the peak left ventricular and peak brachial artery pressures. DUR. SYST. $=$ duration of systole in seconds, between onset of ventricular contraction and aortic valve closure. TTI=tension-time index in mm. Hg-sec. (Braunwald and Frahm, 1961).

patients were similar to those observed in the patients studied at operation (Fig. 6; Braunwald et al., 1960a).

In order to exclude the possibility that the duration of diastole rather than the degree of left ventricular filling controlled the mechanical activity of the ventricle, studies were also carried out on patients in whom the ventricular rhythm was regular but in whom variations in ventricular enddiastolic pressure occurred (Braunwald and Frahm, 1961). A representative tracing is reproduced in Fig. 7, obtained from a patient with aortic stenosis and atrio-ventricular dissociation. The left ventricular end-diastolic pressure was highest during the first beat, in which the atrial contribution to ventricular filling was maximal, and as the temporal relation between atrial and ventricular systole became progressively more abnormal, the end-diastolic pressure fell. The strength of ventricular contraction (as reflected in the left ventricular peak systolic pressure, the brachial artery systolic and pulse pressures, the peak left ventricular-brachial artery pressure gradient, the duration of mechanical systole, and the tension-time index) declined as left ventricular end-diastolic pressure fell. It is apparent, therefore, that even at a constant ventricular rate, the characteristics of ventricular contraction are apparently determined by the ventricular end-diastolic pressure which, in the patient with atrio-ventricular dissociation, is a function of the contribution of atrial systole to ventricular filling, which in turn is dependent upon the temporal relation between atrial and ventricular systole.

Though the investigations on intact unanæsthetized patients with atrial fibrillation and with atrio-ventricular dissociation, using left ventricular end-diastolic pressure, supported the contention that Starling's law is operative in man, it was felt that it was also necessary to relate the strength of contraction to the end-diastolic dimensions or volume of the ventricle. Two techniques were used. In the first, small silver-tantalum clips were sutured to the external surfaces of ventricular chambers at the time of cardiac operations (Fig. 8). Following recovery from operation, and with the patients 
in the intact, unanæsthetized state, cineradiographs were exposed. The distances between any two clips on the individual frames of the cineradiographs were measured, permitting determination of changes in ventricular dimensions throughout a large number of cardiac cycles (Harrison, Goldblatt, and Braunwald, 1963). With this technique, it was shown that phasic changes in ventricular dimensions occur during the respiratory cycle, the changes being more prominent in the right ventricle than in the left. Alterations in ventricular dimensions were more prominent during forced respiration and during the Valsalva manœuvre than during quiet respiration (Goldblatt et al., 1963). The relatively large changes in right ventricular end-diastolic dimensions were considered to result from the alterations in the filling of the right ventricle consequent to changes in intrapleural pressure. Since relatively large beat-to-beat changes in ventricular end-diastolic dimensions occurred during the Valsalva manœuvre, Starling's law could be assessed by relating the enddiastolic dimension to the subsequent degree of shortening of the segment of heart muscle between the points of attachment of the clips (Fig. 9). When end-diastolic dimensions diminished, as venous return to the right ventricle was impeded during the period of positive intrathoracic pressure of the Valsalva manœuvre, the extent of shortening during systole decreased, and vice versa. Similar observations were made in four other patients, and the results again support the view that Starling's law is operative in intact man.

The second technique involved the measurement of ventricular end-systole volume, end-diastolic volume, and stroke volume by a biplane angiocardiographic technique (Dodge et al., 1960). During the performance of left ventricular angiocardiograms, beat-to-beat variations in end-diastolic volume were sometimes noted, and these were related to the stroke volume of the subsequent beat 


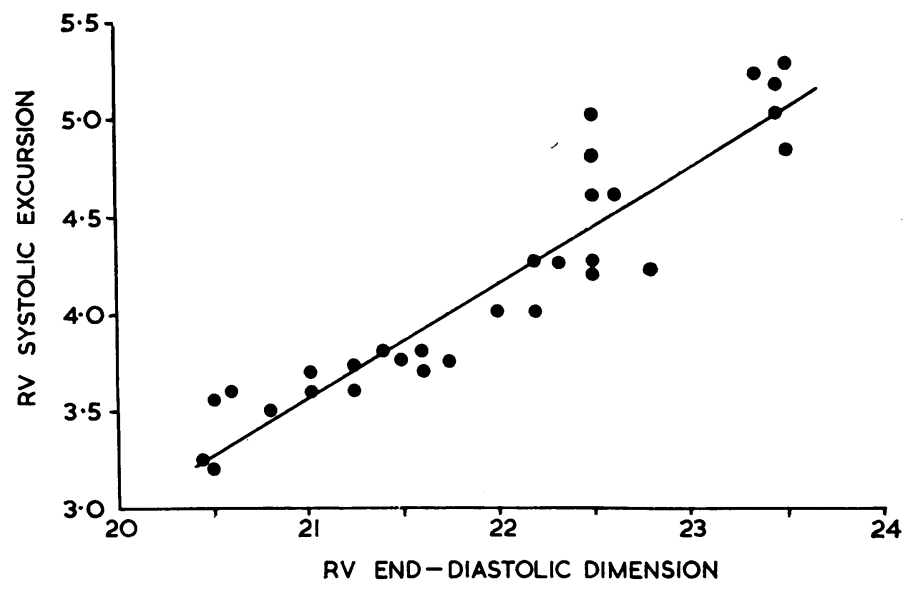

FIG. 9.-Beat-to-beat relation between right ventricular (RV) enddiastolic dimensions and systolic shortening during the subsequent cycle in a patient with sinus rhythm during and after release of a Valsalva manœuvre.

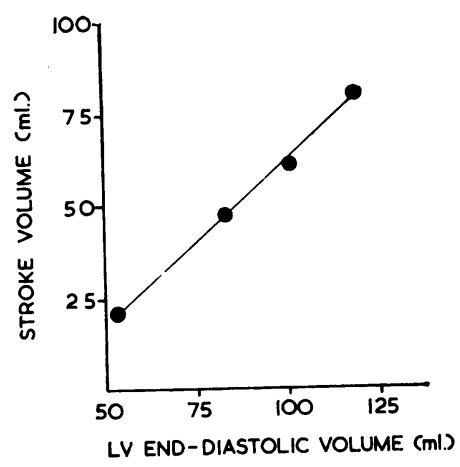

FIG. 10.-Beat-to-beat relation between left ventricular ( $\mathrm{LV}$ ) enddiastolic volume and stroke volume determined angiocardiographically.

(Gleason and Braunwald, 1962). In every patient in whom such variations in end-diastolic volume occurred the subsequent stroke volume always varied with the end-diastolic volume (Fig. 10). In some instances the $R-R$ intervals did not change in the same direction as the end-diastolic volume, but the stroke volume always correlated with the latter variable. When no beat-to-beat changes in left ventricular end-diastolic volume occurred, stroke volume remained constant. Thus, the results of these experiments again support the concept that Starling's law of the heart operates in intact unanæsthetized human subjects.

In the classic experiments of Patterson, Piper, and Starling (1914) upon which the Linacre lecture was primarily based (Starling, 1918), the ventricle was stressed by increasing venous return (raising the venous reservoir leading to the right atrium) or by augmenting the resistance to left ventricular ejection (constricting the outflow cannula). Under both conditions the isolated heart-lung preparation responded by at first increasing its end-diastolic volume and then augmenting its contractile activity to meet the increased load placed upon it. In view of the fundamental importance of these two experimental interventions (increased preload and increased afterload) in the evolution of Starling's law, it was thought necessary to simulate these stresses in order to examine the Starling principle in a more definitive manner in man.

In the past, infusion of intravenous fluids has been employed in attempts to reproduce in man the increase in venous return to the Starling heart-lung preparation. A variety of fluids has been used in such studies, including saline, dextran, glucose solutions, and human serum albumin. In general the results have been conflicting, with a few investigators noting an increase both in filling pressure and cardiac output, while in the majority of studies no consistent relation between these variables was noted. Indeed, in most human subjects the augmentation of the total blood volume has not been associated with a consistent increase in cardiac output. The possibility was considered that the presence of an actively functioning autonomic nervous system in the intact state and its absence in the heart-lung preparation accounts for the difference in the response to infusion in man and to increased venous return in the heart-lung preparation.

In order to study this possibility, the effects of a relatively large rapid blood transfusion $(1500 \mathrm{ml}$. in 90 minutes) on the circulatory dynamics of normal subjects were compared in the control state, and after ganglionic blockade with trimethaphan $(\operatorname{arfonad} R)$. In the control state, the transfusion produced relatively small and inconsistent changes in the so-called central blood volume (right atrium to brachial artery) (average change $=+1 \%$ ), cardiac output $(\mathrm{av} .=+10 \%)$, stroke volume 

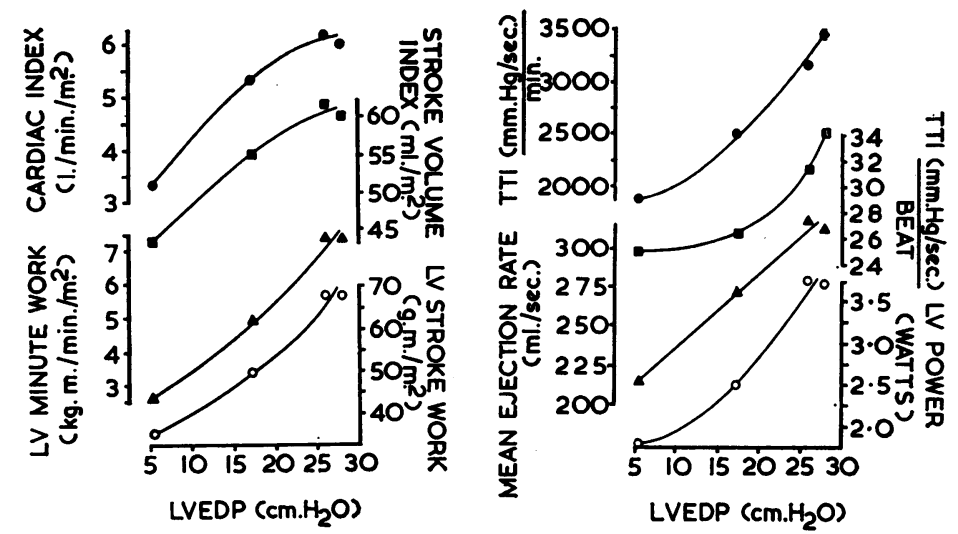

FIG. 11.-Relation between effective left ventricular end-diastolic pressure (LVEDP) and a number of variables that describe the mechanical activity of the LV. Measurements were made in a steady state, and changes occurred consequent to blood infusion (Braunwald et al., 1961).

$(\mathrm{av} .=-3 \%)$, and left ventricular stroke work (av. $=+20 \%$ ). However, when these studies were carried out in identical fashion in the same subjects following inhibition of the activity of the autonomic nervous system by means of ganglionic blockade, the transfusion now resulted in consistent increases of "central" blood volume (av. $=+36 \%$ ), cardiac output (av. $=+44 \%$ ), stroke volume $(\mathrm{av} .=+53 \%$ ), and stroke work (av. $=+108 \%$ ) (Frye and Braunwald, 1960). These observations suggested that when hypervolæmia is induced acutely in intact man, striking alterations in circulatory dynamics are buffered by the activity of the autonomic nervous system. Perhaps reflex venodilatation and reflex depression of the heart's contractile state prevent the acute expansion of the subject's blood volume from having an effect resembling that occurring after an increase of venous return to the heart-lung preparation. Thus, Starling's law of the heart cannot be readily tested by changing the blood volume in subjects with an intact autonomic nervous system. However, after the activity of the autonomic nervous system has been inhibited, striking hæmodynamic changes occur following transfusion, changes that resemble those noted when venous return to the Starling heart-lung preparation is increased.

The experiments just described served to set the stage for an examination of the applicability of Starling's law of the heart in man by augmenting blood volume, and thereby increasing venous return (Braunwald, Frahm, and Ross, 1961). In six subjects, changes in effective left ventricular filling pressure were assessed by simultaneously measuring left ventricular end-diastolic pressure by the transseptal method and intra-œsophageal pressure with a balloon. Again, the autonomic nervous system was inhibited with trimethaphan, and large volumes of blood were infused. In the control state, i.e. during trimethaphan infusion, but just before the blood transfusion, the cardiac indices averaged $3 \cdot 151 . / \mathrm{min} . / \mathrm{m} .{ }^{2}$ and the effective left ventricular end-diastolic pressure averaged $4 \cdot 8 \mathrm{~cm} . \mathrm{H}_{2} \mathrm{O}$. At the completion of the transfusion this pressure had risen to an average level of $22 \cdot 2 \mathrm{~cm} . \mathrm{H}_{2} \mathrm{O}$ and the cardiac indices averaged $4.931 . / \mathrm{min} . / \mathrm{m} .{ }^{2}$. In every instance the stroke volume, left ventricular stroke work, left ventricular power, duration of ejection, and the mean rate of left ventricular ejection also rose progressively during the infusion. In addition, the tension-time index, i.e. the hæmodynamic variable that correlates most closely with myocardial oxygen consumption (Sarnoff $e t$ al., 1958), also rose along with left ventricular end-diastolic pressure (Fig. 11). These data are again consistent with the hypothesis that under the conditions of these experiments, the effective ventricular end-diastolic pressure is an important determinant of the characteristics of ventricular contraction, and that Starling's law of the heart is applicable to man.

Thus, after having shown that when end-diastolic volume or pressure, i.e. the preload, is increased the human heart is capable of reacting in a manner similar to that of the heart-lung preparation, it 
remained to be determined how an increase in the afterload affects the dynamics of ventricular contraction. Accordingly, the resistance to left ventricular ejection was raised by means of the infusion of angiotensin, a pressor agent that, in the concentrations employed, primarily constricts the peripheral vascular bed and has only minimal direct effects upon the heart (Downing and Sonnenblick, 1963).

When graded doses of angiotensin were infused into subjects with normal hearts, or into patients with mild forms of heart disease that did not affect the left ventricle, large increases in left ventricular stroke work resulted (Fig. 12, Group 1). When left ventricular stroke work was plotted against ventricular end-diastolic pressure, i.e. when ventricular function or modified Starling curves were constructed (Sarnoff and Berglund, 1954), the initial portions of the curves were steep, relatively large elevations of stroke work occurring with small increases in ventricular end-diastolic pressure (Ross and Braunwald, 1964a). The curves became less steep when left ventricular end-diastolic pressure exceeded $12 \mathrm{~mm}$. $\mathrm{Hg}$. In contrast to the results in these subjects in whom left ventricular function was considered to be normal, the ventricular function curves were quite different in patients with left ventricular disease, a wide spectrum of responses to increasing resistance to left ventricular outflow being observed. In patients with left ventricular disease without heart failure, large increases in left ventricular end-diastolic pressure were accompanied by small increases in stroke work (Fig. 12, Group 2 ), and in those patients with the most severely depressed ventricular function, left ventricular enddiastolic pressure rose but stroke work remained constant or even declined (Fig. 12, Group 3). Thus, since cardiac dilatation and a fall in cardiac output occurred when the resistance to ventricular emptying was increased in a heart-lung preparation with depressed function (Patterson et al., 1914), the heart of intact, unanæsthetized man again behaved in a manner not dissimilar from the Starling heart-lung preparation, when it was challenged by an increased afterload (Ross and Braunwald, 1964a).

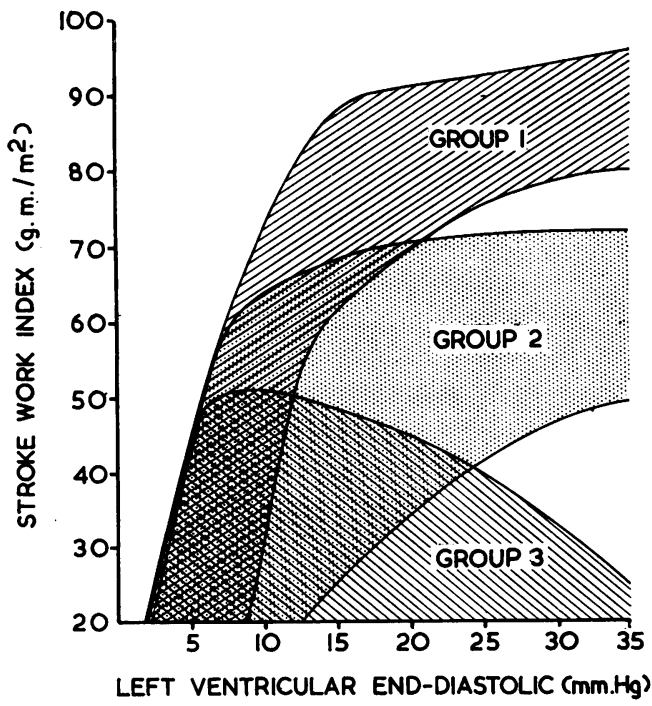

FIG. 12.-Diagrammatic representation of the ranges of the left ventricular function curves produced by angiotensin infusion in three groups of patients (Ross and Braunwald, 1964a).

In the experiments of Starling and his collaborators, a progressive mechanical stress (increased filling or increased resistance to ejection) resulted first in an augmentation of the mechanical activity of the ventricle (ascending limb of the Starling curve), but as the stress was continued the mechanical activity of the heart diminished in spite of further cardiac dilatation (descending limb of the curve). Our attention was then directed to the question of whether patients with heart failure may be on a descending limb of the curve relating left ventricular end-diastolic pressure to stroke work. If this were the case, a sudden decrease in venous return might be expected to raise left ventricular stroke work, while lowering ventricular end-diastolic pressure. In 5 subjects with normal left ventricular function, and in 9 patients with congestive heart failure due to impaired left ventricular function, venous return was decreased by inflating a balloon in the inferior vena cava. In no patient with left ventricular failure was a descending limb of the left ventricular function curve apparent, i.e. as left ventricular end-diastolic pressure fell, ventricular stroke work either remained constant or declined (Ross and Braunwald, 1964b). On the other hand, as has already been noted (Fig. 12, Group 3), when a further stress is placed on the diseased left ventricle by means of angiotensin infusion, a descending limb may readily be demonstrated (Ross and Braunwald, 1964a). It would therefore appear that under the conditions of these studies, patients with left ventricular failure appear to be 
operating near the peak of their Starling curves, which none the less are flattened or depressed when compared with the normal. Similarly, a descending limb was never seen in the patients in whom beat-to-beat alterations in ventricular dimensions were recorded (Braunwald et al., 1960a). From the studies using the myocardial strain gauge arch, it was also apparent that considerable stretching of the ventricle was required before the descending limb of the length-active tension curve was reached (Aygen and Braunwald, 1962).

Since the classic studies of A. V. Hill, it has been known that the fundamental mechanical properties of skeletal muscle can be expressed by the relation between the force generated and the velocity of shortening, i.e., the force-velocity relation (Hill, 1938). Recently, this concept has been extended to isolated mammalian cardiac tissue (Abbott and Mommaerts, 1959; Sonnenblick, 1962) and currently, attempts are being made in our laboratory to extend the force-velocity relation to the human heart (Sonnenblick et al., 1964). These studies have been carried out with isolated papillary muscles obtained from patients undergoing mitral valve replacement, as well as by determining the velocity of myocardial shortening with radio-opaque clips sewn to the surface of the ventricles of unanæsthetized patients. Preliminary observations suggest that the force-velocity relation, studied both in vitro and in the intact states, apply to the human heart, i.e. at any given muscle length or ventricular dimension, the velocity of shortening varies inversely with the load, and that the forcevelocity relation is useful in characterizing the heart's contractile properties.

The investigations described above, when viewed as a whole, demonstrated the fundamental importance of ventricular end-diastolic volume or pressure in the regulation of the contractile activity of the human heart, and thereby extended the applicability of the Frank-Starling mechanism to the human heart. In addition, evidence was obtained that fundamental similarities existed between mammalian skeletal muscle and human myocardium, in respect to the relation between length, resting tension, and active tension, as well as to the relation between the force of contraction and the velocity of shortening. However, these studies should not be interpreted to imply that these intrinsic mechanisms are the only ones that regulate the force of ventricular contraction. Indeed, Starling (1920) appreciated the great importance of neurohumoral adjustments in adapting the heart's activity to the body's requirements. As Sarnoff and Mitchell (1962) have pointed out, alterations of the heart's neurohumoral environment, particularly changes in the catecholamine background, will determine the level of the function curve on which the ventricle is operating. Considerable recent work has emphasized the importance of the activity of the adrenergic nervous system in the regulation of myocardial performance (Rushmer, Smith, and Franklin, 1959; Sarnoff and Mitchell, 1962). The efforts of our laboratory have been directed towards assessing the importance of this system in man.

Evidence for the fundamental importance of the adrenergic nervous system can be obtained by determining the effects of muscular exercise on cardiac dimensions. In studies on unanæsthetized dogs, Rushmer and his associates noted that the diameter of the left ventricle usually decreased while running on a treadmill, but they commented on the variability of this response (Rushmer et al., 1959). We have now determined the effects of pedalling a bicycle ergometer in the supine position on the dimensions of the left and/or right ventricles of 15 patients by measuring the distances between radio-opaque clips on sequential frames of cineradiographs (Braunwald et al., 1963b). These patients had only trivial abnormalities of cardiac function and their responses might be considered analogous to what might be expected in normal subjects investigated under similar conditions. In every patient studied the ventricular dimensions decreased throughout the entire cardiac cycle and the changes were of approximately the same magnitude in both ventricles (Fig. 13). The observed diminutions in external ventricular dimensions during exercise approximated 50 per cent of the stroke volume.

The increased mechanical activity of the heart that occurs during exercise, coupled with a fall in ventricular end-diastolic size and an increase in the rate of development of ventricular pressure (dp/dt) and in the rate of emptying (Fig. 13), clearly suggested the possibility that augmented activity of the adrenergic nervous system was involved in this response. Further evidence for the potential 


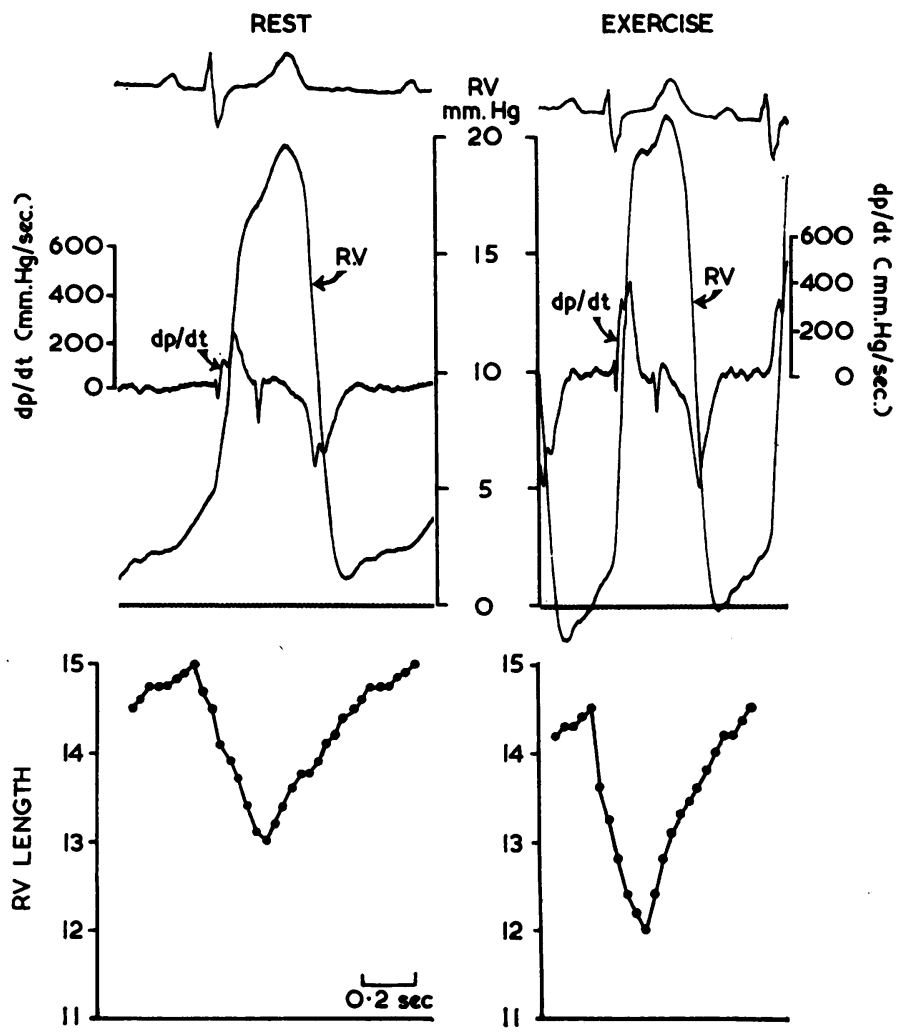

FIG. 13.-Simultaneous recording of RV (right ventricular) pressure, rate of pressure change (dp/dt) and length, at rest, and during exercise. RV pressure measured by means of intracardiac manometer, RV length measured by radio-opaque clip method.

importance of the adrenergic nervous system in the regulation of myocardial contractility was provided by determining the direct effects of electrical stimulation of the stellate ganglion in man (Fig. 14). This was carried out by Dr. A. G. Morrow at the time of left thoracotomy, and it was observed consistently that the force of ventricular contraction, as recorded with a myocardial strain gauge arch, increased significantly, even though the length of the segment of myocardium to which the strain

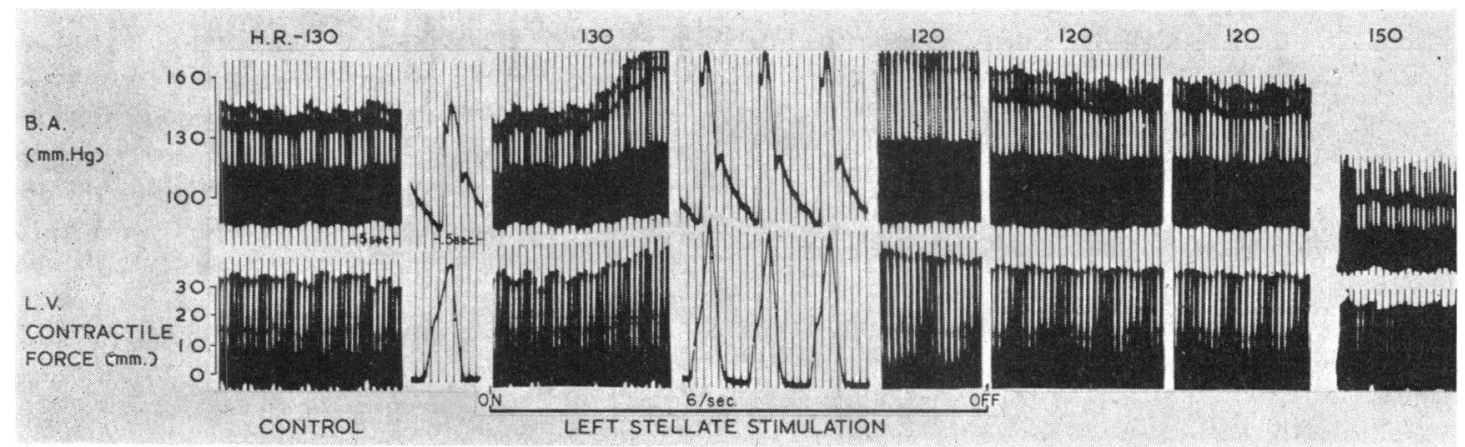

FIG. 14.-Effect of stimulating the left stellate ganglion on brachial artery (BA) pressure and on left ventricular (LV) contractile force, measured with a strain gauge arch. 
gauge arch was sewn remained constant. From this study it seemed clear that stimulation of nervous pathways in the sympathetic nervous system might result in profound augmentation of the contractile state of the myocardium. However, it cannot be concluded from such stimulation experiments that the ordinary activity of the adrenergic nervous system has a significant effect on myocardial function in intact man.

This problem was approached by studying the circulatory effects of muscular exercise before and after pharmacological inhibition of the autonomic nervous system. The investigations were carried out on a group of healthy male subjects, studied in the supine position (Kahler, Gaffney, and Braunwald, 1962). Measurements of heart rate, cardiac output, arterial blood pressure, and oxygen consumption were made at rest and during exercise. The control study was performed without prior drug administration. Oral guanethidine was then begun and the dose was progressively increased every other day for a period of 21 to 25 days. The maximum daily dose of guanethidine ranged from 50 to $85 \mathrm{mg}$. while atropine was given intravenously in a dose of $2 \mathrm{mg}$. just before the second study. Exercise consisted of pedalling a bicycle ergometer at a constant rate. The effects of exercise were determined after guanethidine administration and then under the influence of both atropine and guanethidine.

The conditions of exercise were identical during the control period and after administration of guanethidine and atropine. This was reflected in the finding that the increase in total body oxygen consumption associated with the exercise was identical under both conditions. It was observed that pharmacological inhibition of the autonomic nervous system greatly reduced the magnitude of the circulatory response to exercise. During the control study, a level of exercise that resulted in a fourto fivefold increase in oxygen consumption produced average increases above resting values of 68 per cent in heart rate, 17 per cent in the stroke volume, 96 per cent in the cardiac output, and 129 per cent in left ventricular minute work. After the administration of atropine and guanethidine, identical levels of exercise resulted in average increases above resting values of only 28 per cent in the heart rate, 1 per cent in the stroke volume, 30 per cent in cardiac output, and 5 per cent in left ventricular minute work (Fig. 15). The absolute values of cardiac output, systemic arterial pressure, and ventricular work per minute and per beat were significantly lower and the values of the arteriovenous oxygen differences were significantly higher during exercise following atropine and guanethidine than during the control study.

Blockade of the parasympathetic nervous system alone raised the heart rate, cardiac output, and left ventricular minute work at rest and did not interfere with the circulatory response to exercise. Guanethidine alone slowed the resting heart rate, but did not affect cardiac output or arterial pressure at rest. The cardiac output, mean arterial pressure, and left ventricular work during exercise were lower after guanethidine than during the control study. These studies demonstrate the important contribution made by the autonomic nervous system to the circulatory response to exercise in man and indicate that the sympathetic division plays the major role in this regard.

The logical next step was to attempt to determine whether this system played a compensatory role in maintaining ventricular contractility when the function of the myocardium was depressed in patients with heart disease. The availability of drugs, such as guanethidine, that selectively block the activity of the adrenergic nervous system has made it possible to estimate the role of this system in the maintenance of myocardial function in man. The effects of the administration of guanethidine to patients with reduced cardiovascular reserve were first determined (Gaffney and Braunwald, 1963). In addition to the theoretical interest of such studies, the widespread clinical use of adrenergic blocking drugs in patients with heart disease makes an evaluation of the effects of these drugs on myocardial function of immediate and practical importance. Ten adult patients with inactive rheumatic valvular or primary myocardial disease were studied. Each patient had signs or symptoms of right and/or left-sided congestive heart failure at the time of the investigation. The administration of guanethidine increased the clinical manifestations of heart failure in each of five patients who were in functional classes III or IV. In these patients guanethidine resulted in an increase of dyspnœa and orthopnœa, a decrease in urinary sodium excretion, and a rise in venous pressure and 

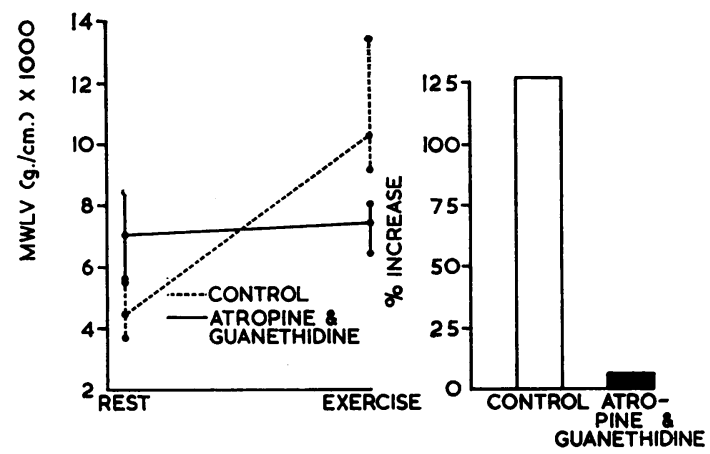

FIG. 15.-Mean and range of values for left ventricular minute work made at rest and during exercise in 7 normal subjects before and after treatment with atropine and guanethidine (Kahler et al., 1962). On the left values, and on the right the percentage increase.

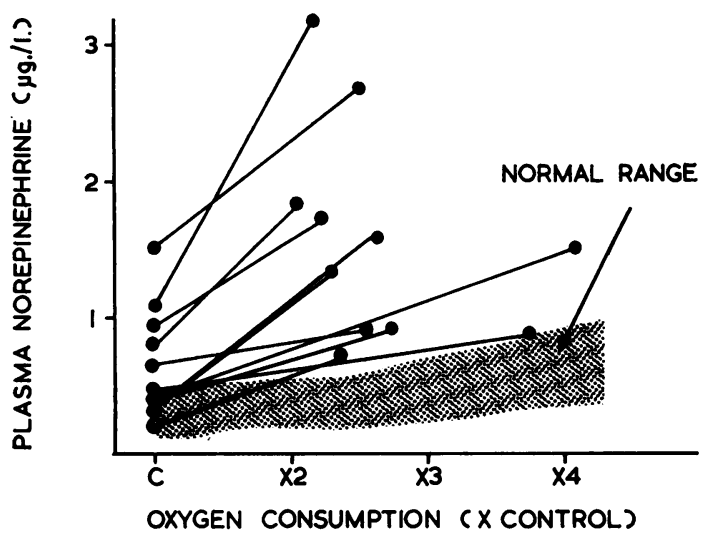

FIG. 17.-Changes in plasma norepinephrine during exercise in patients with congestive heart failure (CHF). $\quad \mathrm{C}=$ control or resting values. The $\mathrm{O}_{2}$ consumption during the exercise period is expressed in multiples of the resting oxygen consumption. The normal range is represented by the stippled area (Chidsey et al., 1962).

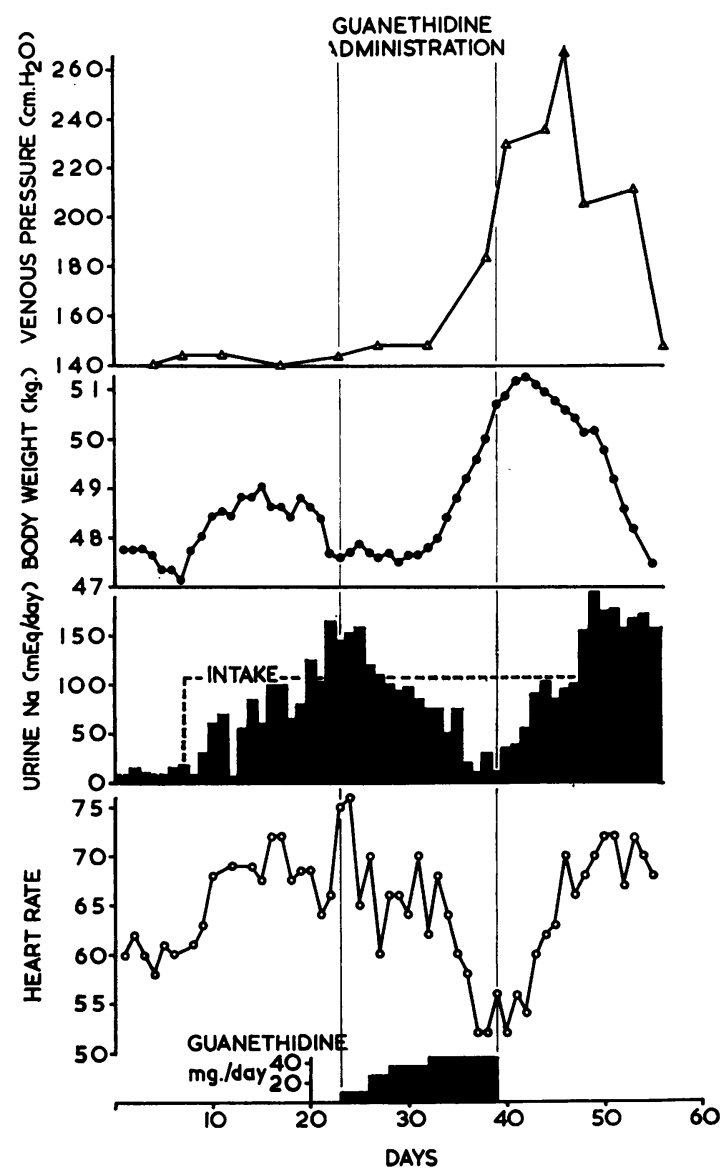

FIG. 16.-Changes in venous pressure, body weight, sodium balance, and heart rate, before, during, and after the administration of guanethidine (Gaffney and Braunwald, 1963).

weight (Fig. 16). The administration of guanethidine to the other five patients, who were in functional classes II or III, did not result in any worsening of the congestive heart failure.

It is evident from these studies that interference with the activity of the adrenergic nervous system is capable of aggravating congestive heart failure in some patients with cardiac decompensation. This effect occurred despite the fact that the adrenergic nerve blockade was almost certainly incomplete. These observations, therefore, suggest that the adrenergic nervous system plays an important compensatory role in the circulatory adjustments of patients to congestive heart failure; and they emphasize the need for caution in the use of anti-adrenergic drugs, such as reserpine and guanethidine, in the treatment of patients with limited cardiac reserve.

It then became of interest to assess the activity of the sympathetic nervous system in patients with heart disease during the stress of muscular exercise and to compare it with the activity in normal subjects. An index of the activity of the sympathetic nervous system at rest and during exercise was obtained by measuring the concentration of norepinephrine in arterial blood. In normal subjects, very small increases in the arterial norepinephrine concentrations were noted during 
exercise (Chidsey, Harrison, and Braunwald, 1962). Though the levels of exercise were comparable, the augmentations of plasma norepinephrine induced by exercise in patients with congestive heart failure exceeded those observed in the normal subjects (Fig. 17). This excessive rise in the circulating norepinephrine concentration is considered to reflect an increased activity of the sympathetic nervous system. Since, as already noted, increased activity of the sympathetic nervous system augments myocardial contractility, it is possible that the heightened sympathetic activity observed during exercise in patients with heart failure plays an important role in supporting their myocardial function.

In view of these findings, we wondered if this massive barrage of sympathetic nerve impulse over prolonged periods affected the concentration of the neurohumoral transmitter, norepinephrine, in the

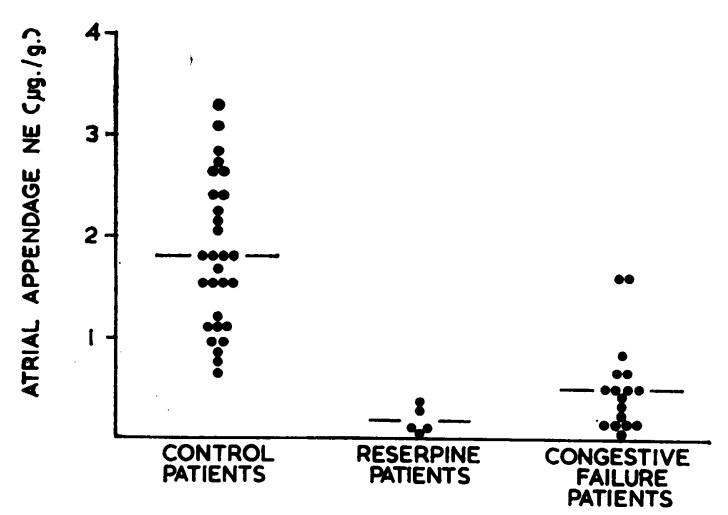

FIG. 18.-Concentration of norepinephrine in the atrial appendages excised at operation in 29 "control" patients who had not been in congestive heart failure, in 5 patients without failure who had been treated with reserpine, and in 17 patients who had been in congestive heart failure (Braunwald et al., 1963).

heart. The concentration of norepinephrine in biopsy specimens of atrial appendage was measured in 29 patients with various cardiac lesions who had not suffered from congestive heart failure and was found to average $1.82 \pm 0.77 \mu \mathrm{g} . / \mathrm{g}$. In 17 patients who had experienced chronic congestive heart failure, the concentration was significantly lower and averaged $0.53 \pm 0.47 \mu \mathrm{g} . / \mathrm{g}$. (Chidsey et al., 1963). Indeed, in 6 of the 17 patients the concentrations of norepinephrine in the atrial appendage were less than $0 \cdot 30 \mu \mathrm{g}$./g. This reduction was similar to that observed when patients without heart failure had been pretreated with reserpine (Fig. 18) (Braunwald et al., 1963a).

It was conceivable that the norepinephrine per unit weight of tissue was reduced in the patients with heart failure simply because the number of adrenergic nerve endings was diluted by the presence of increased amounts of fibrous tissue or hypertrophied myocardium or both. In order to exclude this possibility the total norepinephrine content of papillary muscles excised at the time of mitral valve replacement was determined and reductions in the total quantity of norepinephrine, not merely the concentration, in patients with heart failure has been confirmed (Chidsey and Morrow, 1964). In addition, in guinea-pigs with left heart failure produced by supravalvular aortic constriction, the total quantity of norepinephrine in the heart is substantially reduced (Spann, Chidsey, and Braunwald, 1964). Similar results have been obtained in analyses of the hearts of dogs with congestive heart failure produced by tricuspid regurgitation and pulmonary constriction (Chidsey et al., 1964).

The clinical significance of this biochemical abnormality in the hearts of patients with congestive heart failure remains to be elucidated. It does not appear to be a primary abnormality: it seems more likely that the reduction in the norepinephrine concentration and content in the hearts of many patients with congestive heart failure results secondarily from a prolonged intensive barrage of sympathetic nerve impulses which serve to bolster the activity of the failing heart. However, since norepinephrine depletion alone is capable of reducing myocardial contractility (Lee and Shideman, 1959), it seems quite likely that the norepinephrine depletion that occurs in clinical heart failure further intensifies the heart failure state.

From the investigations reviewed above the following tentative hypothesis regarding the role of the autonomic nervous system in circulatory regulation might be suggested. The adrenergic nervous system increases its stimulation of the myocardium at a time when an imbalance, or a potential imbalance, exists between the cardiac output and the perfusion requirements of the peripheral 
tissues. Such an imbalance may occur in the patient with congestive heart failure at rest, in whom withdrawal of sympathetic stimulation by guanethidine may result in an intensification of heart failure. However, the withdrawal or reduction of sympathetic impulses does not induce cardiac decompensation in normal subjects, or in patients with heart disease who are not suffering from congestive heart failure. One possible explanation for this finding is that the sympathetic nervous system contributes little to the maintenance of cardiac activity in such subjects when they are at rest. An alternative possible explanation is that in the absence of cardiac failure an augmentation of the force of cardiac contraction through the operation of the Frank-Starling mechanism can still take place in spite of any depression of myocardial function evoked by the withdrawal of sympathetic impulses.

During the stress of muscular exercise the function of the adrenergic nervous system assumes greater importance. In patients with congestive heart failure the intense activity of this system is reflected in the extremely high levels of circulating catecholamines which may occur under these conditions. Even in normal subjects, however, the autonomic nervous system plays a significant role in stimulating the myocardium during muscular exercise. This increased activity is reflected by the augmentation of the urinary excretion of norepinephrine and the tendency for the circulating norepinephrine concentration to increase slightly. Inhibition of the adrenergic nervous system alone prevents the small increase in stroke volume that normally occurs during exercise. Adrenergic blockade, however, still permits an increase in cardiac output to occur as a result of a greater increase in heart rate, presumably mediated through the withdrawal of vagal impulses. When the parasympathetic nervous system is blocked in addition to the sympathetic, the circulatory response to exercise is further reduced, and the mixed arteriovenous oxygen difference during exercise rises significantly above the levels encountered in the subjects in whom the autonomic nervous system is intact.

\section{CONCLUSIONS}

Our present concepts of the control of ventricular function in the normal and diseased human heart point to the importance of two fundamental regulatory mechanisms. It might be appropriate to consider one of these, the Frank-Starling mechanism, to be intrinsic to the heart muscle, the mechanical activity of which is determined to a major extent by its length at the onset of ventricular contraction. On the other hand, the release of catecholamines by sympathetic nerve endings and by the adrenal medulla might be considered an extrinsic control mechanism, which can modulate the mechanical activity of the heart at any given end-diastolic fibre length. It seems fruitless at this time to engage in polemics by championing the relative importance of either the intrinsic or the extrinsic mechanism. As already demonstrated, it is possible to design experiments that will emphasize the importance of either one. In normal intact man, however, all the evidence now available suggests that both mechanisms are continuously operative, and that sufficient reserve is available to both the Frank-Starling mechanism and the adrenergic nervous system so that the organism can fall back on one if the other is interfered with. On the other hand, in the presence of serious myocardial disease the reserve of both systems is encroached upon as the heart dilates and resting sympathetic tone increases. Under these conditions removal of the stimulation of myocardial contraction afforded either by an augmented end-diastolic fibre length or by the sympathetic nerves cannot be tolerated.

The author acknowledges with pleasure the collaboration of a number of colleagues in the design, execution, and interpretation of the experiments reviewed above. Particular attention is directed to the contributions of Dr. J. Ross, Jr., C. A. Chidsey, M. M. Aygen, R. L. Kahler, T. E. Gaffney, E. H. Sonnenblick, and A. G. Morrow.

\section{REFERENCES}

Abbott, B. C., and Mommaerts, W. F. H. M. (1959). A study of inotropic mechanisms in the papillary muscle preparation. J. gen. Physiol., 42, 533.

Aygen, M. M., and Braunwald, E. (1962). Studies on Starling's law of the heart. VIII. Mechanical properties of human myocardium studied in vivo. Circulation, 26, 516.

Blix, M. (1895). Die Länge und die Spannung des Muskels. Skand. Arch. Physiol., 5, 173. 
Braunwald, E., Chidsey, C. A., Mason, D. T., and Morrow, A. G. (1963a). Effects of reserpine and of congestive heart failure on the myocardial norepinephrine concentration in man. Trans. Ass. Amer. phycns, 76, 254.

, and Frahm, C. J. (1961). Studies on Starling's law of the heart. IV. Observations on the hemodynamic functions of the left atrium in man. Circulation, 24, 633.

,$- \frac{}{-}$, and Ross, J., Jr. (1961). Studies on Starling's law of the heart. V. Left ventricular function in man. J. clin. Invest., 40, 1882.

- - Frye, R. L., Aygen, M. M., and Gilbert, J. W., Jr. (1960a). Studies on Starling's law of the heart. III. Observations in patients with mitral stenosis and atrial fibrillation on the relationships between left ventricular enddiastolic segment length, filling pressure, and the characteristics of ventricular contraction. J. clin. Invest., 39, 1874.

- and Ross, J., Jr. (1960b). Studies on Starling's law of heart. II. Determinants of the relationship between left ventricular end-diastolic pressure and circumference. Circulat. Res., 8, 1254.

—- Goldblatt, A., Harrison, D. C., and Mason, D. T. (1963b). Studies on cardiac dimensions in intact, unanesthetized man. III. Effects of muscular exercise. Circulat. Res., 13, 460.

Chidsey, C. A., Braunwald, E., Morrow, A. G., and Mason, D. T. (1963). Myocardial norepinephrine concentration in man: effects of reserpine and of congestive heart failure. New Engl. J. Med., $269,653$.

- Harrison, D. C., and Braunwald, E. (1962). Augmentation of the plasma nor-epinephrine response to exercise in patients with congestive heart failure. New Engl. J. Med., 267, 650.

—, Kaiser, G., Sonnenblick, E. H., Spann, J. F., and Braunwald, E. (1964). Cardiac norepinephrine stores in experimental heart failure in the dog. J. clin. Invest. In the press.

heart failure. Clin. Res., 12, 178.

Dodge, H. T., Sandler, H., Ballew, D. W., and Lord, J. D. (1960). The use of biplane angiocardiography for the measurement of left ventricular volume in man. Amer. Heart J., 60, 762.

Downing, S. E., and Sonnenblick, E. H. (1963). Effects of continuous administration of angiotensin II on ventricular performance. J. appl. Physiol., 18, 585.

Fick, A. (1882). Mechanische Arbeit und Warmeent-wickelung bei der Muskeltkätigheit. Brockhaus, Leipzig.

Frank, O. (1895). Zur Dynamik des Herzmuskels. Z. Biol., 32, 370.

Frye, R. L., and Braunwald, E. (1960). Studies on Starling's law of the heart. I. The circulatory response to acute hypervolemia and its modification by ganglionic blockade. J. clin. Invest., 39, 1043.

Gaffney, T. E., and Braunwald, E. (1963). The importance of the adrenergic nervous system in the support of circulatory function in patients with congestive heart failure. Amer. J. med., 34, 320.

Gleason, W. L., and Braunwald, E. (1962). Studies on Starling's law of the heart. VI. Relationships between left ventricular end-diastolic volume and stroke volume in man with observations on the mechanisms of pulsus alternans. Circulation, 25, 841.

Goldblatt, A., Harrison, D. C., Glick, G., and Braunwald, E. (1963). Studies on cardiac dimensions in intact, unanesthetized man. II. Effects of respiration. Circulat. Res., 13, 455.

Harrison, D. C., Goldblatt, A., and Braunwald, E. (1963). Studies on cardiac dimensions in intact, unanesthetized man. I. Description of techniques and their validation. Circulat. Res., 13, 448.

Hill, A. V. (1938). The heat of shortening and the dynamic constants of muscle. Proc. roy. Soc. Lond. B., $126,136$.

Kahler, R. L., Gaffney, T. E., and Braunwald, E. (1962). The effects of autonomic nervous system inhibition on the circulatory response to muscular exercise. J. clin. Invest., 41, 1981.

Kries, J. von (1892). Untersuchungen zur Mechanik des quergestreiften Muskels. Arch. Anat. Physiol. (Lp. 3), Physiol. Abt., p. 1.

Lee, W. C., and Shideman, F. E. (1959). Role of myocardial catecholamines in cardiac contractility. Science, 129, 967.

Patterson, S. W., Piper, H., and Starling, E. H. (1914). The regulation of the heart beat. J. Physiol. (Lond.), $48,465$.

Ross, J., Jr., and Braunwald, E. (1964a). The study of left ventricular function in man by increasing resistance to ventricular ejection with angiotensin. Circulation. In the press.

mance of the normal and failing human left ventricle. Circulation. In the press.

, - , and Morrow, A. G. (1959). Transseptal left atrial puncture: New technique for the measurement of left atrial pressure in man. Amer. J. Cardiol., 3, 653.

Rushmer, R. F., Smith, O., and Franklin, D. (1959). Mechanisms of cardiac control in exercise. Circulat. Res., 7,602 .

Sarnoff, S. J., and Berglund, E. (1954). Ventricular function. I. Starling's law of the heart studied by means of simultaneous right and left ventricular function curves in the dog. Circulation, 9, 706.

—, Braunwald, E., Welch, G. H., Jr., Case, R. B., Stainsby, W. N., and Macruz, R. (1958). Hemodynamic determinants of oxygen consumption of the heart with special reference to the tension-time index.. Amer.J.Physiol., 192, 148

- and Mitchell, J. H. (1962). The control of the function of the heart. In Handbook of Physiology. Section 2: Circulation, Vol. 1, p. 490. Washington, D.C. American Physiological Society.

Sonnenblick, E. H. (1962). Force-velocity relations in mammalian heart muscle. Amer. J. Physiol., $202,931$.

-, Glick, G., Morrow, A. G., and Braunwald, E. (1964). Force-velocity relations in the human heart. J. clin. Invest., 43, 1245.

Spann, J. F., Chidsey, C. A., and Braunwald, E. (1964). Reduction of norepinephrine in experimental heart failure. Science. In the press.

Starling, E. H. (1918). The Linacre Lecture on the Law of the Heart. (Cambridge, 1915). Longmans, Green, London.

- (1920). On the circulatory changes associated with exercise. J. roy. Army med. Cps, 34, 258. 